Neurosurg Focus 24 (6):E2, 2008

\title{
Pyogenic brain abscess
}

\author{
Ersin ErdoĞan, M.D., and Tufan Cansever, M.D. \\ Department of Neurosurgery, Gulhane Military Medical School, Ankara, Turkey
}

\begin{abstract}
$\checkmark$ Brain abscesses have been one of the most challenging lesions, both for surgeons and internists. From the beginning of the computed tomography (CT) era, the diagnosis and treatment of these entities have become easier and less invasive. The outcomes have become better with the improvement of diagnostic techniques, neurosurgery, and broad-spectrum antibiotics. Atypical bacterial abscesses are more often due to chemotherapy usage in oncology, long life expectancy in patients with human immunodeficiency virus (HIV) infection, and immunosuppression in conjunction with organ transplantation. Surgical treatment options showed no significant difference with respect to mortality levels, but lower morbidity rates were achieved with stereotactically guided aspiration. Decompression with stereotactically guided aspiration, antibiotic therapy based on results of pus culture, and repeated aspirations if indicated from results of periodic CT follow-up scans seem to be the most appropriate treatment modality for brain abscesses. Immunosuppression and comorbidities, initial neurological status, and intraventricular rupture were significant factors influencing the outcomes of patients. The pitfalls and evolution in the diagnosis and treatment of brain abscesses are discussed in this study. (DOI: $10.3171 /$ FOC/2008/24/6/E2)
\end{abstract}

\section{KEY Words • abscess incidence • brain abscess • outcome • stereotaxy • treatment options}

I N 1893, Sir William Macewen reported only 1 death in 19 patients suffering from brain abscess. ${ }^{15}$ Unfortunately, until the advent of the CT modality, the outcomes in patients with brain abscess were not as satisfactory as in Macewen's series. Use of CT and MR imaging, evolution of microbiological diagnostic techniques, and production of broad-spectrum antibiotics have improved outcomes in the past 20-25 years. The routine use of CT scanning has facilitated the diagnosis of brain abscess and made the patients' follow-up safer. ${ }^{12,23,65,80,100}$ The mortality rate decreased from a range of $22.7-45 \%^{2,7,17,79,99,104}$ to $0-$ $20 \%{ }^{64,92}$ after the routine use of CT scans. Before the advent of CT scanning, brain abscesses were mostly diagnosed intraoperatively and resected totally. ${ }^{65,104}$ However, easier and safer diagnostic techniques made stereotactic aspiration a favorable treatment option, especially in multiple and noncortical lesions. ${ }^{22,64,73,74}$ Also, in some cases CT scanning enables safe and successful medical treatment without any surgical intervention. ${ }^{6,21,64,65,80,81}$ Nevertheless, there is no consensus on treatment of brain abscess; the necessity of surgical intervention and the type of surgical procedure are still doubtful.

\section{Demographic Factors}

Brain abscesses are seen in 1500-2500 cases/year in

Abbreviations used in this paper: $\mathrm{ADC}=$ apparent diffusion coefficient; $\mathrm{CHD}=$ congenital heart disease; $\mathrm{CNS}$ = central nervous system; $\mathrm{CSF}=$ cerebrospinal fluid; $\mathrm{DW}=$ diffusion weighted; $\mathrm{MCA}=$ middle cerebral artery. the US, with a higher incidence in developing countries. ${ }^{37}$ There were more male than female patients; ratios from 1.3:1 to 3.0:1 have been reported. ${ }^{18,49,62,88}$ The patients ranged in age from infants to elderly individuals. ${ }^{34,49,62,64,79,88}$ Roche et al. ${ }^{79}$ reported that most brain abscesses occur in the first 2 decades of life. However, their opinion was based on literature published several decades ago, when intracranial complications of sinus/otitis infections, a common childhood infection, were seen more frequently. ${ }^{44,62}$, 66,75,87 Even Roche et al. ${ }^{79}$ found the incidence of brain abscesses in children to be lower than they had expected from earlier reports. However, some authors reported that the incidence in patients $<15$ years of age was no more than $15-30 \% .^{18,41,49,88}$

\section{Origins of Abscesses}

Cerebral abscess occurs in patients with the following predisposing states: 1) contiguous purulent spread (for example, frontal sinus infection leading to frontal lobe abscess, sphenoid sinus infection leading to cavernous sinus extension, and middle ear/mastoid air cell infection leading to temporal lobe and cerebellar abscess); 2) hematogenous or metastatic spread (for example, pulmonary infections and arteriovenous shunts, congenital heart disease and endocarditis, dental infections, and gastrointestinal infections); 3) head trauma; 4) neurosurgical procedure; and 5) immunosuppression.

According to the earlier literature, ${ }^{46,67,81,104}$ the most common predisposing factor for brain abscesses was direct spread from the middle ear, meninges, mastoid infections, 
and paranasal sinus. Before the 1980s, CHD (6-50\%) and sinus/otitis infections seem to have been the most common

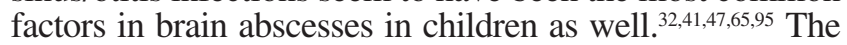
evolution in diagnostic techniques, antimicrobial agents, and advances in cardiovascular surgery caused a decrease in the ratio of brain abscesses due to CHD and sinus/otitis infections and an increase in lesions found in patients receiving immunosuppressive therapy due to transplantation procedures, in patients with HIV who had a prolonged life expectancy, and in those receiving chemotherapy for cancer treatment. More abscesses arose after the 1980s in infants and immunosuppressed patients, and were diagnosed at earlier ages ( $<6$ months). ${ }^{34}$ Nowadays, hematogenous or metastatic spread has become the most common factor in the formation of brain abscess. ${ }^{37}$

The organisms that cause brain abscess are typically bacterial in origin. Peptostreptococcus and Streptococcus spp (especially $S$. viridans and microaerophilic organisms) are mostly identified in patients with cardiac disorders (cyanotic heart disease) and right-to-left shunt bypasses that exclude the normal filtration mechanisms of the pulmonary vascular tree. In CHD, diminished arterial oxygen saturation and increased blood viscosity may cause focal cerebral ischemia and act as a nidus for multiple infections, especially in the gray-white matter junction, often in the MCA distribution. ${ }^{26,32,41,47,94,95}$ At one time CHD was a significant predisposing factor in children's lesions, but there has been a decline in these cases due to advances in cardiac surgery and the use of broad-spectrum antibiotics.

Bacteroides, Peptostreptococcus, and Streptococcus spp are most commonly identified in brain abscesses caused by contiguous spread. This spread is the result of osteomyelitis in the neighboring air sinus. The risk of a brain abscess developing in an adult with active chronic otitis media is $1 / 10,000$ per year, but in a 30-year-old patient with active infection, the lifetime risk becomes $\sim 1 / 200{ }^{71,72}$

Streptococcus, S. aureus, Pseudomonas, and Bacteroides spp are mostly identified in pulmonary infections (pulmonary abscess, empyema, bronchiectasis). They are located mostly in the MCA distribution and often multiply.

Staphylococcus, Streptococcus, Clostridium, and Enterobacter spp are mostly identified in patients with open head trauma. Gunshot wounds, open depressed skull fractures with foreign bodies in brain parenchyma, and basal skull fracture with CSF fistula cause brain abscesses, generally contiguous with the site of trauma. ${ }^{16,18,27,28,34,35,51}$

Staphylococcus and Streptococcus spp are identified in patients with prior neurosurgical procedures. Wounds that are open $>4$ hours are subject to a higher risk of infection. Additional risk factors include implantation of a foreign body such as a shunt or external ventricular drain, highgrade gliomas, and early irradiation after surgical procedures. ${ }^{16,100}$

Fungal infections, Toxoplasma, Staphylococcus, Streptococcus, and Pseudomonas spp are identified in immunocompromised patients with HIV infections, organ transplantation, chemotherapy, or steroid use. ${ }^{106}$ Branched hyphal-form fungal infections (for example, aspergillosis) obstruct large- and intermediate-sized vessels, causing cerebral arterial thrombosis and infarction. ${ }^{90}$ Sterile infarcts may be converted to septic infarcts with associated formation of an abscess. . $3,325,26,68,90$ Abscesses can also result from contiguous spread..$^{25}$ These lesions are mostly located in the posterior fossa and lobes of the cerebrum. The mortality rates due to fungal abscesses range from 75 to $100 \%$, despite intensive treatment with amphotericin B. ${ }^{26,68,69}$

There continues to be a strong representation of anaerobes (30-50\%) in patients with brain abscesses. Additionally, atypical bacteria such as Nocardia and Actinomyces spp may occur in immunocompromised patients. Careful culturing of abscess material obtained at the time of surgery provides the best opportunity to make a microbiological diagnosis. Although positive culture rates have approached $100 \%$ in studies with meticulous handling of clinical specimens ${ }^{66}$ the incidence of negative cultures remains as high as $15-30 \%$ in most series, ${ }^{19,65,76,98,104}$ especially in patients in whom antimicrobial therapy is started before operation. Polymerase chain reaction analysis of 16 S recombinant DNA and sequencing may identify pathogens to the species level directly from brain abscesses. This approach is rapid and is especially useful in the identification of slow-growing and fastidious organisms. ${ }^{97}$

Lumbar puncture has been considered hazardous in patients with brain abscess. ${ }^{19,84}$ It is usually performed because of a strong suspicion of concomitant meningitis and/ or ventriculitis, and yields only $10-30 \%$ positive CSF cultures in which organisms similar to those grown in abscess cultures are found. ${ }^{19,84,99}$ Although a significant proportion of the deaths was thought to be caused by lumbar puncture during early work, ${ }^{67}$ a recent study in which multivariate regression was used failed to reveal such a hazard. ${ }^{78}$ Therefore, lumbar puncture could be justified in patients with brain abscess in the absence of increased intracranial pressure and in whom there are clear manifestations of meningitis and/or ventriculitis.

\section{Pathogenesis of Brain Abscesses}

Brain abscesses develop in response to a parenchymal infection with pyogenic bacteria, which begins as a localized area of cerebritis and evolves into a suppurative lesion surrounded by a well-vascularized fibrotic capsule. Staging of brain abscesses in humans has been based on findings obtained during CT scans or MR imaging sessions. The early stage or early cerebritis occurs from Days 1 to 3 and is typified by neutrophil accumulation, tissue necrosis, and edema. Microglial and astrocyte activation is also evident at this stage and persists throughout abscess development. The intermediate, or late cerebritis stage, occurs from Days 4 to 9 and is associated with a predominant macrophage and lymphocyte infiltrate. The final or capsule stage occurs from Day 10 onward and is associated with the formation of a well-vascularized abscess wall, in effect sequestering the lesion and protecting the surrounding normal brain parenchyma from additional damage. Early capsule formation develops from Days 10 to 13 and tends to be thinner on the medial or ventricular side of the abscess and prone to rupture in this direction. After Day 14, late capsule formation develops, with gliotic, collagenous, and granulation layers. $^{12}$

In addition to limiting the extent of infection, the immune response that is an essential part of abscess formation also destroys surrounding normal brain tissue. This is supported by findings in experimental models, in which lesion sites are greatly exaggerated compared to the local- 


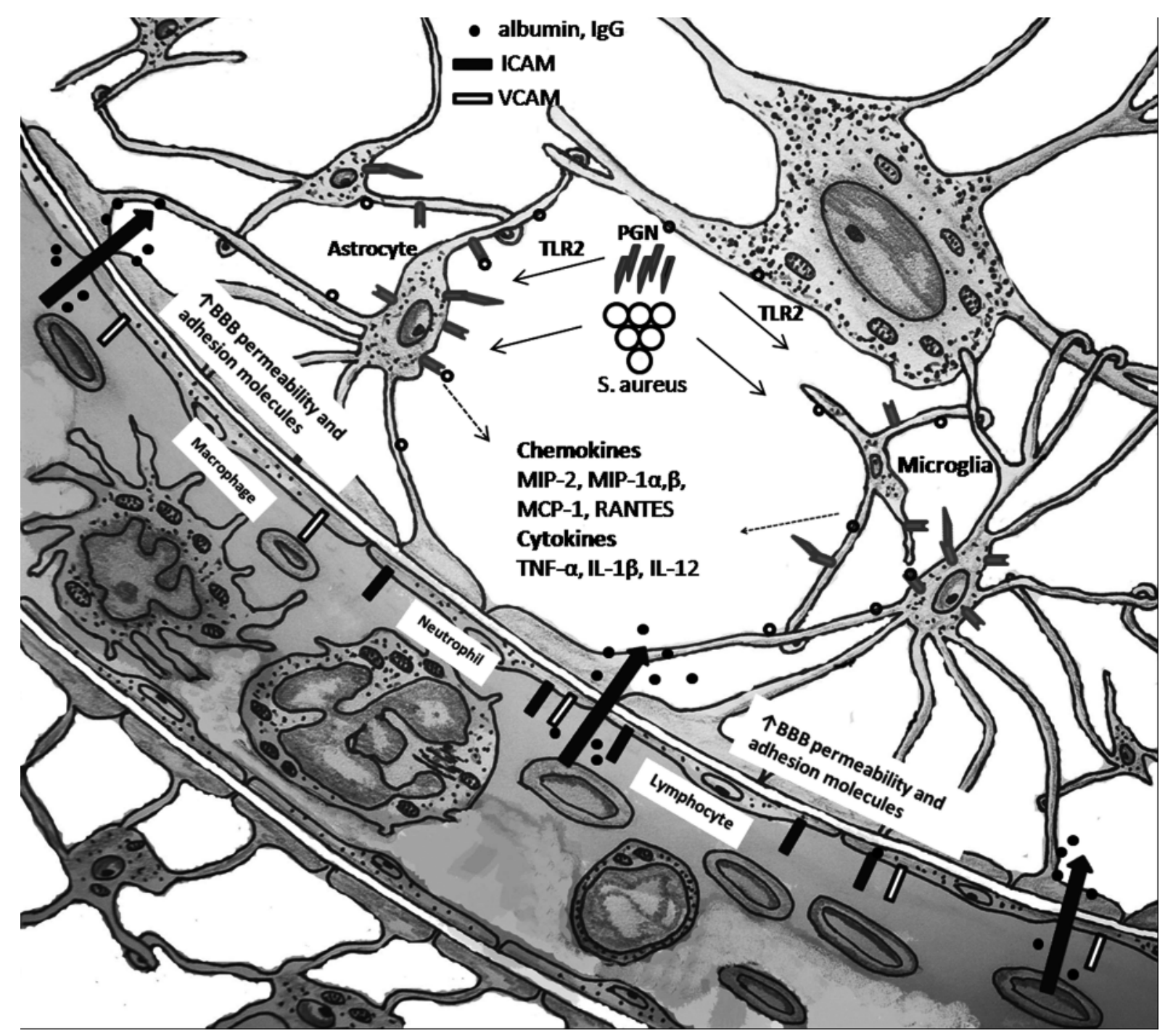

FIG. 1. Schematic showing how pyogenic bacteria such as $S$. aureus induce a localized suppurative lesion typified by direct damage to brain parenchyma and subsequent tissue necrosis. Bacterial recognition of peptidoglycan (PGN) from the cell wall by Toll-like receptor 2 (TLR2) leads to the activation of resident astrocytes and microglia; the elaboration of numerous proinflammatory cytokines and chemokines leading to increased blood-brain barrier (BBB) permeability; and the entry of macromolecules such as albumin and immunoglobulin $\mathrm{G}(\mathrm{IgG})$ into the brain parenchyma. In addition, cytokines induce the expression of adhesion molecules (intercellular adhesion molecule [ICAM] and vascular cell adhesion molecule [VCAM]), which facilitate the extravasation of peripheral immune cells such as neutrophils, macrophages, and $\mathrm{T}$ cells into the evolving abscess. Newly recruited peripheral immune cells can be activated by both bacteria and cytokines released by activated glia. $\mathrm{IL}=$ interleukin; $\mathrm{MCP}=$ monocyte chemoattractant protein; $\mathrm{MIP}=$ macrophage inflammatory protein; RANTES = regulated on activation, normal T cell expressed and secreted; $\mathrm{TNF}=$ tumor necrosis factor.

ized nature of bacterial growth, reminiscent of an overactive immune response..$^{52}$ This phenomenon is also observed in human brain abscess, in which lesions can encompass a large portion of brain tissue, often spreading well beyond the initial focus of infection. Therefore, controlling the intensity and/or duration of the antibacterial immune response in the brain may allow for effective elimination of bacteria while minimizing damage to surrounding brain tissue (Fig. 1).

As mentioned earlier, lesion sites in both experimental models and in human brain abscesses are greatly exaggerated compared to the localized nature of bacterial growth, reminiscent of an overactive immune response. To account for the enlarged region of affected tissue involvement associated with brain abscesses compared to the relatively focal nature of the initial insult, Kielian et al ${ }^{54}$ have proposed that proinflammatory mediator production following $S$. aureus infection persists, effectively augmenting damage to surrounding normal brain parenchyma. Specifically, the continued release of proinflammatory mediators by activated glia and infiltrating peripheral immune cells may act through a positive feedback loop to potentiate the subsequent recruitment and activation of newly recruited inflammatory cells and glia. ${ }^{53}$ This would effectively perpetuate 
the antibacterial inflammatory response through a vicious pathological circle culminating in extensive collateral damage to normal brain tissue.

Recent studies support persistent immune activation associated with experimental brain abscesses, in which elevated levels of interleukin- $1 \beta$, tumor necrosis factor $-\alpha$, and macrophage inflammatory protein -2 have been detected between 14 and 21 days after $S$. aureus exposure. ${ }^{54}$ Concomitant with prolonged proinflammatory mediator expression, $S$. aureus infection was found to induce a chronic disruption of the blood-brain barrier, which correlated with the continued presence of peripheral immune cell infiltrates and glial activation. ${ }^{53,54}$ Collectively, these findings suggest that intervention with antiinflammatory compounds subsequent to sufficient bacterial neutralization may be an effective strategy to minimize damage to surrounding brain parenchyma during the course of brain abscess development, leading to improvements in cognition and neurological outcomes. ${ }^{54}$ The responses of microglia and astrocytes to $S$. aureus have been elucidated in terms of proinflammatory mediator expression, and in general have been found to be qualitatively similar to those observed following lipopolysaccharide exposure. ${ }^{4} \mathrm{Al}-$ though studies with primary microglia and astrocytes from Toll-like receptor 2 knockout mice reveal an important role for this receptor in mediating $S$. aureus-dependent activation, it is clear that additional receptors are also involved in glial responses to this bacterium..$^{54}$ This functional redundancy is not surprising because these pathogens have the potential for devastating consequences in tissue such as the CNS, which has limited regenerative capacity. The implications of glial cell activation in the context of brain abscess are probably several. First, parenchymal microglia and astrocytes may be involved in the initial recruitment of professional bactericidal phagocytes into the CNS through their elaboration of chemokines and proinflammatory cytokines. Second, microglia exhibit $S$. aureus bactericidal activity in vitro, suggesting that they may also participate in the initial containment of bacterial replication in the CNS. However, their bactericidal activity in vitro is not comparable to that of neutrophils or macrophages, suggesting that this activity may not be a major effector mechanism for microglia during acute infection. Third, activated microglias have the potential to influence the type and extent of antibacterial adaptive immune responses through their upregulation of major histocompatibility complex class II and costimulatory molecule expression. Finally, if glial activation persists in the context of ongoing inflammation, the continued release of proinflammatory mediators could damage surrounding normal brain parenchyma.

\section{Clinical Presentation}

There are no pathognomonic clinical signs; most patients present with clinical signs that depend on the location or mass effect of the lesion: headache, nausea, emesis, fever, alteration in consciousness, seizures, and motor weakness are the most common symptoms. ${ }^{16}$ These symptoms are more rapidly progressive, however, with respect to tumoral lesions. Fever is not uniformly seen, and only $30-55 \%$ of patients have a fever $>38.5^{\circ} \mathrm{C} .{ }^{41}$ Seizures are a presenting sign in $16-50 \%$ of patients. ${ }^{16,18,34,103}$ Focal neurological def- icits are seen in 40-60\% of patients, depending on the location of the lesion. ${ }^{16,18,41,103}$ Papilledema is rare in patients $<$ 2 years of age. Patent sutures and low ability to limit the infection and cranial enlargement can occur. Nevertheless, the triad of symptoms of brain abscess (headache, fever, and neurological deficit) can be seen in only $15-30 \%$ of patients. ${ }^{16,103}$ If the lesion is located in the brainstem, mostly in the pons (2\%), cranial nerve palsies, motor weakness, and many different symptoms may be present and deterioration tends to be more rapid.

\section{Diagnosis}

Imaging features of a brain abscess depend on the stage at the time of imaging as well as the source of infection. ${ }^{14}$ Brain abscess development can be divided into 4 stages: 1 ) early cerebritis (1-4 days); 2) late cerebritis (4-10 days); 3 ) early capsule formation (11-14 days); and 4) late capsule formation ( $>14$ days). ${ }^{39}$ The majority of abscesses demonstrate considerable surrounding edema, which generally presents during the late cerebritis or early capsule formation stage, secondary to mass effect. Hematogenous abscesses, which can be seen in the setting of endocarditis, cardiac shunts, or pulmonary vascular malformations, are usually multiple, identified at the gray-white junction, and located in the MCA territory.

In the earlier phases, a CT scan performed without addition of contrast may show only low-attenuation abnormalities with mass effect. In later phases, a complete peripheral ring may be seen. On CT scans obtained after administration of contrast material, uniform ring enhancement is virtually always present in later phases. In early phases the capsule will be difficult to visualize via conventional techniques, and double contrast CT often is helpful in defining encapsulation of abscess. Metastatic tumors, high-grade gliomas, cerebral infarction, resolving cerebral contusion or hematoma, lymphoma, toxoplasmosis, demyelinating disease, and radiation necrosis must be kept in mind as the differential diagnosis for brain abscesses appearing as ring-enhancing lesions..$^{1,82}$ The advanced techniques in neuroradiology have facilitated the diagnosis of multiple brain abscesses. The incidence of multiple brain abscesses, which was reported as $1.8-17 \%$ of patients ${ }^{16,65,67}$ $, 81,104$ in the pre-CT era, is $23-50 \%$ in modern-day cases. ${ }^{16,18 \text {, }}$ $21,34,98,103$

The MR imaging findings also depend on the stage of the infection. In the early phase, lesions revealed on MR images can have a low signal on T1-weighted and a high signal on T2-weighted images, with patchy enhancement. In later phases, the low signal on T1-weighted images becomes better demarcated, with a high signal on T2-weighted images, both in the cavity and surrounding parenchyma. The abscess cavity shows a hyperintense rim on T1weighted images obtained without contrast and a hypointense rim on T2-weighted images. ${ }^{40}$ As on CT scanning, MR imaging usually demonstrates a ring of enhancement surrounding the abscess. ${ }^{91}$ Abscesses tend to grow toward the white matter, away from the better-vascularized gray matter, with thinning of the medial wall. ${ }^{50}$ However, the enhancing-ring sign is nonspecific and must be evaluated in the context of the clinical history. Thickness, irregularity, and nodularity of the enhancing ring are suggestive of 


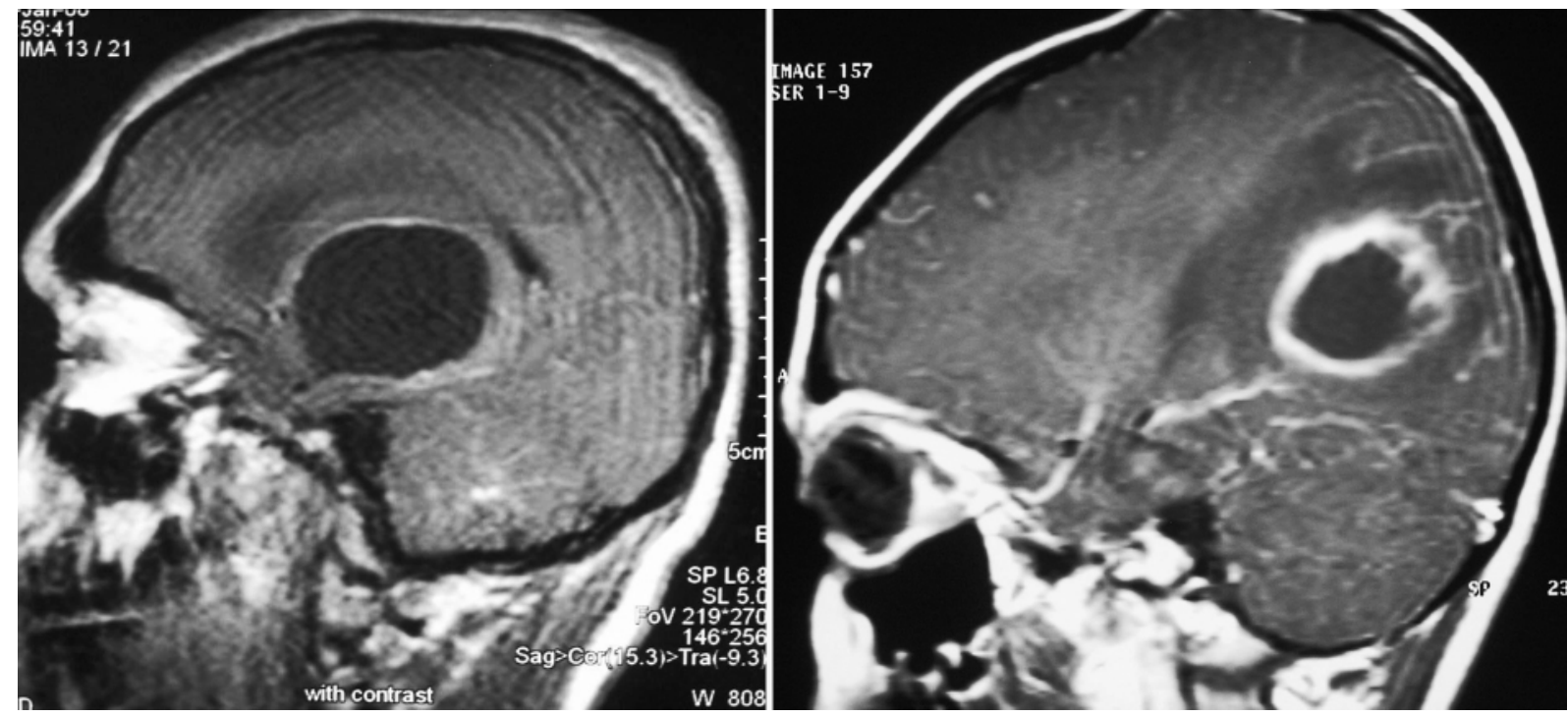

FIG. 2. Sagittal T1-weighted MR images obtained in different patients after administration of contrast material, demonstrating ring-enhancing cystic lesions. Left: Admission MR image revealing a thin, homogeneous, well-circumscribed cystic lesion with mild perilesional edema. The pathological examination revealed a cystic pilocytic astrocytoma. Right: Admission MR image demonstrating a thick, heterogeneous (thicker on the cortical, thinner on the ventricular side), well-circumscribed lesion with extensive perilesional edema and contrast enhancement due to vasculitis and cerebritis of the surrounding parenchyma. The pathological and microbiological examinations revealed pyogenic brain abscess.

tumor (the majority of cases), or possibly fungal infection (Fig. 2)..$^{40}$ On DW images, restricted diffusion (bright signal) may be seen; this helps to differentiate abscesses from necrotic neoplasms, which are not usually restricted, ${ }^{20,39}$ although not all abscesses follow this rule. Fungal and tuberculous abscesses may have elevated diffusivity and low signal on DW imaging. ${ }^{40}$

Several studies demonstrate the utility of DW imaging in differentiating between necrotic or cystic lesions and brain abscesses. ${ }^{20,39}$ Brain abscesses demonstrate increased signal on the trace images and reduced ADC, whereas necrotic neoplasms demonstrate decreased signal on the trace image and high ADC values. Initially, DW imaging was thought to be helpful in differentiation of toxoplasmosis from lymphoma.

In 1 study an ADC threshold of 0.8 was proposed, where ADC ratios $<0.8$ would favor lymphoma over toxoplasmosis; however, that study showed a significant overlap in ADC values in toxoplasmosis and lymphoma. ${ }^{86}$ The authors concluded that in the majority of patients, $\mathrm{ADC}$ ratios are not definitive in making the distinction between toxoplasmosis and lymphoma. Nevertheless, DW imaging has a high sensitivity for detection of early acute ischemic changes in cortical and deep white matter that can occur in cases of infectious vasculitis. The brain abscess cavity shows regions of increased fractional anisotropy values, with restricted mean diffusivity compared with other cystic intracranial lesions. This information may prevent misinterpretation of the diffusion tensor imaging information as white matter fiber bundle abnormalities associated with mass lesions ${ }^{38}$ Intracerebral abscesses are characterized by specific resonances on MR spectroscopy that are not detected in normal or in sterile diseased human tissue. The MR spectroscopy modality has been shown to be specifi- cally useful in differentiating between brain abscesses and other cystic lesions ${ }^{13}$ which is information that can be used to expedite implementation of the appropriate antimicrobial therapy. Metabolic substances, such as succinate (2.4 $\mathrm{ppm})$, acetate $(1.9 \mathrm{ppm})$, alanine $(1.5 \mathrm{ppm})$, amino acids $(0.9 \mathrm{ppm})$, and lactate $(1.3 \mathrm{ppm})$, can all be present in untreated bacterial abscesses or soon after the initiation of treatment. . $^{57}$

\section{Treatment}

There are 3 treatment options for brain abscesses: 1) medical; 2) aspiration (freehand, stereotactically or neuroendoscopically guided); or 3) total excision. In choosing the appropriate treatment option, the following factors must be considered: Karnofsky performance scale score; primary infection; predisposing state; and the number, size, location, and stage of the abscess. Modern-day therapy of brain abscesses generally includes a combined surgical and medical approach. ${ }^{64}$

\section{Medical Management}

Antibiotics play a critical role in the management of brain abscesses. The characteristics of the agent (such as penetration into the brain) and the prior use of intrathecal or interstitial therapy must be known before the treatment. To choose the appropriate antibiotic, the microorganism or underlying illness must be identified. ${ }^{36}$ If the patient is not in sepsis or critical condition, antibiotic therapy should be postponed until culture material is obtained. Mampalam and Rosenblum ${ }^{65}$ reported an eightfold greater number of sterile cultures in patients receiving preoperative antibiotics. Xiao et al. ${ }^{103}$ reported that cultures of intracerebral 
material remained sterile for $39(34 \%)$ of their 115 surgical patients. Of the 76 patients whose cultures were positive, in $68(89 \%)$ a single pathogen was identified and in $8(11 \%)$ 2 pathogens were found. If the predisposing state is hematogenous spread or the patients have symptoms of systemic infection, blood cultures can be useful in identifying the microorganism. Tseng and Tseng ${ }^{98}$ performed blood cultures in 49 of 122 patients who had a clinical presentation of systemic infection (fever and leukocytosis). Only 13 of those patients had blood cultures that grew bacteria (positive rate, 26.5\%); 7 of them had the same pathogen in both blood and brain abscess cultures. Blood culture is the least invasive, cheapest, and fastest way to identify the pathogenic microorganism. Despite low rates of positive findings, blood cultures must be taken in every patient in whom a brain abscess is suspected and who has symptoms of systemic infection.

Medical management alone can be considered if the patients are poor candidates for surgical intervention according to the following criteria: if the lesions are multiple; $<1.5 \mathrm{~cm}$ in diameter; located in eloquent areas; or if there are any concomitant infections like meningitis or ependymitis. The most important objection is to empirical treatment with no microbiological identification; another microorganism may be responsible for the abscess. At least one aspiration procedure would be very useful in identification of the microorganism, if the patient has no coagulopathy.

Medical treatment alone is more successful if the treatment is begun during the cerebritis stage, if the lesion is $<$ $1.5 \mathrm{~cm}$ in diameter, if the duration of symptoms is $<2$ weeks, and if the patient shows clinical improvement within the 1 st week..$^{80}$

Systemic antibiotics were given for 6 weeks, although some centers now prescribe 2 weeks of intravenously administered antibiotics followed by up to 4 weeks of oral antimicrobial therapy. ${ }^{33,65,80}$ If no microorganism can be identified, broad-spectrum therapy for 6-8 weeks may be warranted. ${ }^{29,64}$ Despite appropriate treatment, $5-10 \%$ recurrence rates were reported in brain abscesses, which can be caused by early discontinuation of the treatment. ${ }^{16}$ Jamjoom ${ }^{45}$ reported a series in which the duration of antibiotic therapy was based not on a specific time but rather on normalization of C-reactive protein levels. Additionally, elevated C-reactive protein levels can be used in the differential diagnosis of brain abscess from other ring-enhancing lesions. ${ }^{43}$ Three of 26 patients had persistently elevated Creactive protein levels and were found to have a recurrence of the abscess. There were no recurrences in patients in whom the levels returned to normal. Kutlay et al. ${ }^{56}$ reported that parenteral antibiotics and hyperbaric oxygen therapy were administered for a total of 4 weeks in 13 patients, even in patients without a bacteriological diagnosis. Overall, initial surgery failed in 2 patients (15.3\%). Two abscesses that recurred were again aspirated 6 and 9 days, respectively, after the first procedure. However, long-term radiological evaluation has failed to show a recurrence of abscesses in any of these cases after a mean follow-up period of 9.5 months. The main difference between their study and others reported in the literature is the reduced duration of antibiotic therapy. ${ }^{5,21,65,80}$ Nowadays, with easy radiological follow-up of the brain abscess and broad-spectrum an- tibiotics, practitioners tend to choose medical treatment, especially if the pathogen can be diagnosed based on cultures of blood, CSF, or direct aspiration. Leys et al. ${ }^{60}$ reported on 56 patients who were nonrandomly selected for medical treatment, simple aspiration, or excision of their brain abscess and found no statistically significant difference. In fact, brain abscesses cause too much physiological stress for patients, and surgical stress should not be added if it is not necessary.

Corticosteroids can be used, but they have side effects, and their use in the treatment of vasogenic edema due to brain abscess is still being debated. The negative effect of dexamethasone on capsule formation was shown in an experimental study. ${ }^{77}$ Black et al. ${ }^{8}$ made the same comment about the effect of corticosteroids. However, Schroeder et al. ${ }^{85}$ reported that corticosteroids do not stop the formation of the capsule, and that they only act as a retarding force. Mampalam and Rosenblum ${ }^{65}$ reported a higher mortality rate in the patients treated with corticosteroids, but these patients were in poor neurological condition initially and had decreasing levels of consciousness. These authors recommended corticosteroid usage in patients with significant perilesional edema that was diagnosed radiologically. Sandrock et al. ${ }^{83}$ reported a retrospective study of 26 patients that demonstrated no detrimental effect on outcome when corticosteroids were used in patients with intracranial abscesses. It should be kept in mind that steroids may decrease the contrast enhancement of the abscess capsule in the early stages of infection and that this can be a false indicator of radiological improvement, or it may even delay diagnosis. ${ }^{24}$

\section{Surgical Management}

Throughout the history of neurosurgery, the treatment of brain abscesses has been a challenge. Nonsurgical empirical treatment of suspected small brain abscesses with antibiotics has been advocated. ${ }^{10,29}$ Rational management of intracranial mass lesions requires establishment of a positive diagnosis before implementation of therapeutic measures. Indeed, patients presenting with rapidly progressive neurological deficits that are attributable to the mass effect of the neuroradiologically verified brain abscess are strong candidates for urgent decompression, both for neurosurgeons and internists.

Various types of operative procedures have been used for the treatment of brain abscess. The choice of procedure has been the subject of many debates. ${ }^{70,90,102}$ Craniotomy, which was much advocated in the earlier era when neither antibiotics nor CT scanning was available, is now rarely used. Aspiration, repeated as necessary or with drainage, has widely replaced attempts at complete excision. Nevertheless, an open surgical procedure is still preferred to management of the brain abscess with a combination of medical treatment and surgical evacuation, in the following circumstances: if there is evidence of increased intracranial pressure due to significant mass effect of the brain abscess; if there are difficulties in diagnosis; if the abscess is the result of a traumatic injury that has introduced foreign materials; if the lesion is located in the posterior fossa; and if there is any presumption of fungal infection. Even decompression with a craniotomy or craniectomy will be helpful for patients in poor neurological condition. 
Because a diagnosis based only on clinical and neuroradiological findings can be erroneous, nonsurgical therapeutic decisions should not be made without a positive diagnosis of the pathogen. Stereotactic management of brain abscess, which allows both confirmation of the diagnosis and institution of therapy by aspiration of lesion contents and identification of the offending organism, has become widespread since the introduction of CT-guided stereotaxy. $522,63,64,89,90,93$ A review of the recent literature shows several series of brain abscesses primarily treated with stereotactic techniques. Stapleton et al.,92 reviewing their series of 11 patients, concluded that stereotactic aspiration should be considered the treatment of choice in all but the most superficial and the largest cerebral abscesses. Kondziolka et al. ${ }^{55}$ related the failure of stereotactic treatment of brain abscesses in a series of 29 cases, because of either inadequate aspiration, lack of catheter drainage, long-term immunosuppression, or insufficient antibiotic therapy. Longatti et al. ${ }^{61}$ reported on 4 patients harboring cerebral abscesses who underwent surgery in which the neuroendoscopic technique with freehand stereotaxy was used. They aspirated the pus and washed the cavity with antibiotics. Both Hellwig et al. ${ }^{42}$ and Kamikawa and colleagues $^{48}$ reported their experiences with a flexible scope (freehand or stereotactically guided), whereas Fritsch and Manwaring $^{30}$ opted for a rigid one in a pediatric series. Longatti et al. reported the usefulness of flexible endoscopes in certain crucial surgical actions, such as aspirating and inspecting the abscess in all spatial directions or coping with a firm and elastic membrane that requires scissors or other instruments for its perforation. ${ }^{42,61}$ Hellwig et al. maintained that drainage catheters need not be inserted inside the abscess after endoscopy (to be used for antibiotic infusion and further aspiration during the following days), whereas Fritsch and Manwaring reported placing catheters in all cases. Longatti et al. avoided drain insertion in 1 patient only, and no second operation was needed because no residual abscesses with a space-occupying effect occurred; conversely, Hellwig et al. performed subsequent operations in 4 of their patients. Longatti et al. reported that no significant difference could be found in the length of hospital stay, number of postoperative CT scans, and duration of the antibiotic therapy between traditional and endoscopic stereotactically guided aspiration.

Intraoperative sampling of abscess material and smear preparations for microscopic analysis and identification of the organisms in brain abscess is fraught with pitfalls. First, abscess-related necrosis must be differentiated from tumor necrosis. Small or large areas of coagulation necrosis are frequently seen in glioblastomas. Sometimes the necrotic area of a tumor is taken over by a massive infiltration of polymorphonuclear leukocytes that change the necrotic area into a liquefactive one, leading to the erroneous diagnosis of a brain abscess. On the other hand, perilesional gliosis of an abscess may be so marked as to mimic a lowgrade astrocytoma. Although in a nonneoplastic proliferation of reactive astrocytes the cellularity is usually lower and individual cells are very regular, it is not uncommon to encounter predominantly cellular areas of proliferating astrocytes with pleomorphic and hyperchromatic nuclei. ${ }^{5}$ Barlas et al. categorized brain abscesses as cerebritis (Stage I) when scarce polymorphonuclear leukocytes and perivas- cular erythrocytes were detected and encapsulation (Stage II) when frank pus, polymorphonuclear leukocyte crowding, necrosis, granulation tissue, and dense reactive gliosis were found; this provided a better and simplified understanding of the pathological features and more effective pathological-radiological correlation. On the other hand, advanced neuroradiological techniques can be used for the differential diagnosis of these lesions.

In lesions that are deep seated, multiloculated, and close to the ventricle wall, a reduction of $1 \mathrm{~mm}$ in the distance between the ventricle and brain abscesses will increase the rupture rate by $10 \% .{ }^{59}$ Although a combination of intrathecal and intravenous antimicrobial treatment has been recommended in intraventricular rupture, the therapeutic strategy in this special group of patients remains controversial. ${ }^{11}$ Other therapeutic regimens have been recommended, including the following: 1) urgent craniotomy with rapid evacuation of the abscess; ${ }^{105}$ 2) emergency evacuation with lavage of the ventricles and ventriculostomy placement accompanied by the administration of intraventricular antibiotics; ${ }^{9}$ and 3) a 5-component therapeutic regimen, including open craniotomy with debridement of the abscess cavity, lavage of the ventricular system, intravenous administration of antibiotics for 6 weeks, intraventricular administration of gentamicin twice daily for 6 weeks, and intraventricular drainage for 6 weeks. ${ }^{107}$

\section{Outcome}

The mortality rate ranged from 40 to $60 \%$ in the pre-CT era and was reduced to $10 \%$ from the beginning of the CT era to $2000 .{ }^{94,96,104}$ After 2000 , the mortality rate was reported to be between 17 and 32\%.49,58,62,78,79 This discrepancy may be mainly due to the drastic changes in epidemiology taking place nowadays. Compared to the previous reports, the incidence of brain abscesses caused by sinus/otitis infection decreased, whereas those associated with immunodeficiency increased markedly. It is challenging to cure patients who are receiving chemotherapy for cancer or immunosuppressive therapy for organ transplantation, or who have HIV infection. Xiao et al. ${ }^{103}$ reported 2.8 -fold risk of poor outcome in immunocompromised patients. Other comorbidities like diabetes mellitus or cirrhosis are also factors negatively influencing the outcome.

A much poorer prognosis was reported for patients presenting with lower Glasgow Coma Scale scores. ${ }^{90,94,103}$ Xiao et al. reported that $13(62 \%)$ of the 21 patients with initial Glasgow Coma Scale scores $<9$ either died or fell into a vegetative state. Intraventricular rupture is a devastating and often fatal complication of brain abscess and is associated with a high death rate ${ }^{88,105}$ Death was reported in 109 $(84.5 \%)$ of 129 patients in a review of the literature published between 1950 and 1993. ${ }^{107}$ In another recent study from Japan, ${ }^{94}$ the overall mortality rate was $38.7 \%$ (12 of 31 patients. Lee et al. ${ }^{59}$ reported a series of 62 patients in which $30(48 \%)$ had a poor outcome (severe disabilities, vegetative state, and death) due to intraventricular rupture of the brain abscess. The pretreatment neurological status of the patient is the most influential independent factor related with the outcome.

It is not uncommon for survivors to suffer neurological sequelae including hemiparesis, seizure, and cognitive dys- 
function. ${ }^{16,31,65}$ Seizure is a long-term risk in $30-50 \%$ of patients suffering from brain abscesses. ${ }^{16,18,74}$ The latency period can be as long as 5 years, but is shorter in older patients. ${ }^{74}$ Especially in any tumoral lesion in which antiepileptic treatment is initiated after an attack, antiepileptic prophylaxis must be initiated immediately and continued for at least 1 year due to the high risk of subsequent seizures in patients with brain abscesses. The treatment can be discontinued if no significant epileptogenic activity can be shown on electroencephalograms. The management of the abscess is one of the most important factors both in seizure and neurological outcome. Cansever et al. ${ }^{16}$ reported that, after surgical removal of abscesses, more focal neurological deficits (5.2\% compared with $0 \%$ ) and seizures (47.7\% compared with $31.2 \%$ ) were seen in comparison with stereotactic aspiration. The location of the abscess had no effect on predisposition to seizure. However, the hypodense areas surrounding the cavity of the abscess were wider in surgically treated patients. These areas were thought to be the damaged brain parenchyma that was causing neurological deficits and epileptic activities.

Rates of recurrence are estimated to be $10-50 \%$. The period of surveillance should be continued for at least 1 year. The resolution of the surrounding edema and loss of the enhancing rim must be documented in this period, which can take up to 6 months. ${ }^{101}$ If the patients show no neurological deterioration, imaging can be obtained at 1week intervals with and without addition of contrast in the first 6 weeks. Lesions that do not show any regression should be aspirated again. Surgical therapy may be preferred for patients with neurological deterioration and/or radiologically unresolved lesions.

\section{References}

1. Agarwal AK, Garg R, Simon M: Ring enhancing lesion on CT scan: metastases or a brain abscess? Emerg Med J 24:706, 2007

2. Alderson PO, Gado MH, Siegel BA: Computerized cranial tomography and radionuclide imaging in the detection of intracranial mass lesions. Semin Nucl Med 7:161-173, 1977

3. Ashdown BC, Tien RD, Felsberg GJ: Aspergillosis of the brain and paranasal sinuses in immunocompromised patients: CT and MR imaging findings. AJR Am J Neuroradiol 162:155-159, 1994

4. Baldwin AC, Kielian T: Persistent immune activation associated with a mouse model of Staphylococcus aureus-induced experimental brain abscess. J Neuroimmunol 151:24-32, 2004

5. Barlas O, Sencer A, Erkan K, Eraksoy H, Sencer S, Bayindir C: Stereotactic surgery in the management of brain abscess. Surg Neurol 52:404-411, 1999

6. Barsoum AH, Lewis HC, Cannillo KL: Nonoperative treatment of multiple brain abscesses. Surg Neurol 16:283-287, 1981

7. Beller AJ, Sahar A, Praiss I: Brain abscess. Review of 89 cases over a period of 30 years. J Neurol Neurosurg Psychiatry 36:757-768, 1973

8. Black P, Graybill JR, Charache P: Penetration of brain abscess by systemically administered antibiotics. J Neurosurg 38:705-709, 1973

9. Black PM, Levine BW, Picard EH, Nirmel K: Asymmetrical hydrocephalus following ventriculitis from rupture of a thalamic abscess. Surg Neurol 19:524-527, 1983

10. Boom WH, Tuazon CU: Successful treatment of multiple brain abscesses with antibiotics alone. Rev Infect Dis 7:189-199, 1985

11. Brewer NS, MacCarty CS, Wellman WE: Brain abscess: a review of recent experience. Ann Intern Med 82:571-576, 1975
12. Britt RH, Enzmann DR, Placone RC Jr, Obana WG, Yeager AS: Experimental anaerobic brain abscess. Computerized tomographic and neuropathological correlations. J Neurosurg 60:11481159, 1984

13. Burtscher IM, Holtås S: In vivo proton MR spectroscopy of untreated and treated brain abscesses. AJNR Am J Neuroradiol 20:1049-1053, 1999

14. Calfee DP, Wispelwey B: Brain abscess. Semin Neurol 20: 353-360, 2000

15. Canale DJ: William Macewen and the treatment of brain abscesses: revisited after one hundred years. J Neurosurg 84:133-142, 1996

16. Cansever T, Izgi N, Civelek E, Aydoseli A, Kiris T, Sencer A: Retrospective analysis of changes in diagnosis, treatment and prognosis of brain abscess for a period of thirty-three-years, in 13th World Congress of Neurological Surgery, Marrakesh, June 19-24, 2005. Nyon Vaud, Switzerland: World Federation of Neurosurgical Societies, 2005 (Abstract)

17. Carey ME, Chou SN, French LA: Experience with brain abscesses. J Neurosurg 36:1-9, 1972

18. Carpenter J, Stapleton S, Holliman R: Retrospective analysis of 49 cases of brain abscess and review of the literature. Eur J Clin Microbiol Infect Dis 26:1-11, 2007

19. Chun CH, Johnson JD, Hofstetter M, Raff MJ: Brain abscess. A study of 45 consecutive cases. Medicine (Baltimore) 65:415431, 1986

20. Desprechins B, Stadnik T, Koerts G, Shabana W, Breucq C, Osteaux M: Use of diffusion-weighted MR imaging in differential diagnosis between intracerebral necrotic tumors and cerebral abscesses. AJNR Am J Neuroradiol 20:1252-1257 1999

21. Dyste GN, Hitchon PW, Menezes AH, VanGilder JC, Greene GM: Stereotaxic surgery in the treatment of multiple brain abscesses. J Neurosurg 69:188-194, 1988

22. Ebeling U, Hasdemir MG: Stereotactic guided microsurgery of cerebral lesions. Minim Invasive Neurosurg 38:10-15, 1995

23. Enzmann DR, Britt RH, Lyons BE: Brain abscess. Neurosurgery 16:877-878, 1985

24. Enzmann DR, Britt RH, Placone RC Jr, Obana W, Lyons B, Yeager AS: The effect of short-term corticosteroid treatment on the CT appearance of experimental brain abscesses. Radiology 145:79-84, 1982

25. Epstein NE, Hollingsworth R, Black K, Farmer P: Fungal brain abscesses (aspergillosis/mucormycosis) in two immunosuppressed patients. Surg Neurol 35:286-289, 1991

26. Erdogan E, Beyzadeoglu M, Arpaci F, Celasun B: Cerebellar aspergillosis: case report and literature review. Neurosurgery 50: 874-877, 2002

27. Erdogan E, Gönül E, Seber N: Craniocerebral gunshot wounds. Neurosurg Q 12:1-18, 2002

28. Erdogan E, Izci Y, Gonul E, Timurkaynak E: Ventricular injury following cranial gunshot wounds: clinical study. Mil Med 169:691-695, 2004

29. Everett ED, Strausbaugh LJ: Antimicrobial agents and the central nervous system. Neurosurgery 6:691-714, 1980

30. Fritsch M, Manwaring KH: Endoscopic treatment of brain abscess in children. Minim Invasive Neurosurg 40:103-106, 1997

31. Gaches J, Lebeau J, Daum S, Waks O: [Study of epileptic sequelae in a series of 20 brain abscesses followed up for more than 10 years.] Neurochirurgie 11:441-452, 1965 (Fr)

32. Garvey G: Current concepts of bacterial infections of the central nervous system. Bacterial meningitis and bacterial brain abscess. J Neurosurg 59:735-744, 1983

33. Gillet GR, Garner JE, Bremner DA: Antimicrobial management of intracranial abscess. Aust N Z J Surg 54:253-255, 1984

34. Goodkin HP, Harper MB, Pomeroy SL: Intracerebral abscess in children: historical trends at Children's Hospital Boston. Pediatrics 113:1765-1770, 2004

35. Gönül E, Baysefer A, Kahraman S, Ciklatekerlioglu O, Gezen F, Yayla $\mathrm{O}$, et al: Causes of infections and management results in 
penetrating craniocerebral injuries. Neurosurg Rev 20:177-181, 1997

36. Gortvai P, De Louvois J, Hurley R: The bacteriology and chemotherapy of acute pyogenic brain abscess. Br J Neurosurg 1:189-203, 1987

37. Greenberg MS: Handbook of Neurosurgery, ed 5. New York: Thieme, 2001, pp 217-223

38. Gupta RK, Nath K, Prasad A, Prasad KN, Husain M, Rathore RK, et al: In vivo demonstration of neuroinflammatory molecule expression in brain abscess with diffusion tensor imaging. AJNR Am J Neuroradiol 29:236-332, 2008

39. Guzman R, Barth A, Lövblad KO, El-Koussy M, Weis J, Schroth $\mathrm{G}$, et al: Use of diffusion-weighted magnetic resonance imaging in differentiating purulent brain processes from cystic brain tumors. J Neurosurg 97:1101-1107, 2002

40. Haimes AB, Zimmerman RD, Morgello S, Weingarten K, Becker RD, Jennis R, et al: MR imaging of brain abscesses. AJR Am J Roentgenol 152:1073-1085, 1989

41. Hakan T, Ceran N, Erdem I, Berkman MZ, Göktaş P: Bacterial brain abscesses: an evaluation of 96 cases. J Infect 52:359-366, 2006

42. Hellwig D, Bauer BL, Dauch WA: Endoscopic stereotactic treatment of brain abscesses. Acta Neurochir Suppl (Wien) 61:102105,1994

43. Hirschberg H, Bosnes V: C-reactive protein levels in the differential diagnosis of brain abscesses. J Neurosurg 67:358-360, 1987

44. Infection in Neurosurgery Working Party of the British Society for Antimicrobial Chemotherapy: The rational use of antibiotics in the treatment of brain abscess. Br J Neurosurg 14:525-530, 2000

45. Jamjoom AB: Short course antimicrobial therapy in intracranial abscess. Acta Neurochir (Wien) 138:835-839, 1996

46. Jennett B, Miller JD: Infection after depressed fracture of skull. Implications for management of nonmissile injuries. J Neurosurg 36:333-339, 1972

47. Kagawa M, Takeshita M, Yato S, Kitamura K: Brain abscess in congenital cyanotic heart disease. J Neurosurg 58:913-917, 1983

48. Kamikawa S, Inui A, Miyake S, Kobayashi N, Kasuga M, Yamadori T, et al: Neuroendoscopic surgery for brain abscess. Eur J Paediatr Neurol 1:121-122, 1997

49. Kao PT, Tseng HK, Liu CP, Su SC, Lee CM: Brain abscess: clinical analysis of 53 cases. J Microbiol Immunol Infect 36: 129-136, 2003

50. Karampekios S, Hesselink J: Cerebral infections. Eur Radiol 15: 485-493, 2005

51. Karasu A, Cansever T, Sabanc1 PA, Kiris T, Imer M, Oran E, et al: [Craniocerebral civilian gunshot wounds: one hospital's experience.] Ulus Travma Acil Cerrahi Derg 14:59-64, 2008

52. Kielian T: Immunopathogenesis of brain abscess. J Neuroinflamm 1:16, 2004

53. Kielian T, Esen N, Bearden ED: Toll-like receptor 2 (TLR2) is pivotal for recognition of $\mathrm{S}$. aureus peptidoglycan but not intact bacteria by microglia. Glia 49:567-576, 2005

54. Kielian T, Esen N, Liu S, Phulwani NK, Syed MM, Phillips N, et al: Minocycline modulates neuroinflammation independently of its antimicrobial activity in staphylococcus aureus-induced brain abscess. Am J Pathol 171:1199-1214, 2007

55. Kondziolka D, Duma CM, Lunsford LD: Factors that enhance the likelihood of successful stereotactic treatment of brain abscesses. Acta Neurochir (Wien) 127:85-90, 1994

56. Kutlay M, Colak A, Yildiz S, Demircan N, Akin ON: Stereotactic aspiration and antibiotic treatment combined with hyperbaric oxygen therapy in the management of bacterial brain abscesses. Neurosurgery 57:1140-1146, 2005

57. Lai PH, Li KT, Hsu SS, Hsiao CC, Yip CW, Ding S, et al: Pyogenic brain abscess: findings from in vivo 1.5-t and 11.7-t in vitro proton MR spectroscopy. AJNR Am J Neuroradiol 26:279-288, 2005
58. Le Moal G, Landron C, Grollier G, Bataille B, Roblot F, Nassans $\mathrm{P}$, et al: Characteristics of brain abscess with isolation of anaerobic bacteria. Scand J Infect Dis 35:318-321, 2003

59. Lee TH, Chang WN, Su TM, Chang HW, Lui CC, Ho JT, et al: Clinical features and predictive factors of intraventricular rupture in patients who have bacterial brain abscesses. J Neurol Neurosurg Psychiatry 78:303-309, 2007

60. Leys D, Christiaens JL, Derambure P, Hladky JP, Lesoin F, Rousseaux M, et al: Management of focal intracranial infections: is medical treatment better than surgery? J Neurol Neurosurg Psychiatry 53:472-475, 1990

61. Longatti P, Perin A, Ettorre F, Fiorindi A, Baratto V: Endoscopic treatment of brain abscesses. Childs Nerv Syst 22:1447-1450, 2006

62. Lu CH, Chang WN, Lui CC: Strategies for the management of bacterial brain abscess. J Clin Neurosci 13:979-985, 2006

63. Lunsford LD: Stereotactic drainage of brain abscesses. J Neurosurg 71:154, 1989 (Letter)

64. Mamelak AN, Mampalam TJ, Obana WG, Rosenblum ML: Improved management of multiple brain abscesses: a combined surgical and medical approach. Neurosurgery 36: 76-86, 1995

65. Mampalam TJ, Rosenblum ML: Trends in the management of bacterial brain abscesses: a review of 102 cases over 17 years. Neurosurgery 23:451-458, 1988

66. Mathisen GE, Johnson JP: Brain abscess. Clin Infect Dis 25:763-779, 1997

67. Morgan H, Wood MW, Murphey F: Experience with 88 consecutive cases of brain abscess. J Neurosurg 38:698-704, 1973

68. Nadkarni T, Goel A: Aspergilloma of the brain: an overview. J Postgrad Med 51 (Suppl 1): S37-S41, 2005

69. Ng A, Gadong N, Kelsey A, Denning DW, Leggate J, Eden OB: Successful treatment of aspergillus brain abscess in a child with acute lymphoblastic leukemia. Pediatr Hematol Oncol 17: 497-504, 2000

70. Ng PY, Seow WT, Ong PL: Brain abscesses: review of 30 cases treated with surgery. Aust N Z J Surg 65:664-666, 1995

71. Nunez DA: Aetiological role of otolaryngological disease in paediatric intracranial abscess. J R Coll Surg Edinb 37:80-82, 1992

72. Nunez DA, Browning GG: Risks of developing an otogenic intracranial abscess. J Laryngol Otol 104:468-472, 1990

73. Ohaegbulam SC, Saddeqi NU: Experience with brain abscesses treated by simple aspiration. Surg Neurol 13:289-291, 1980

74. Osenbach RK, Loftus CM: Diagnosis and management of brain abscess. Neurosurg Clin N Am 3:403-420, 1992

75. Osma U, Cureoglu S, Hosoglu S: The complications of chronic otitis media: report of 93 cases. J Laryngol Otol 114:97-100, 2000

76. Pit S, Jamal F, Cheah FK: Microbiology of cerebral abscess: a four-year study in Malaysia. J Trop Med Hyg 96:191-196, 1993

77. Quartey GR, Johnston JA, Rozdilsky B: Decadron in the treatment of cerebral abscess. An experimental study. J Neurosurg 45: 301-310, 1976

78. Qureshi HU, Habib AA, Siddiqui AA, Mozaffar T, Sarwari AR: Predictors of mortality in brain abscess. J Pak Med Assoc 52: 111-116, 2002

79. Roche M, Humphreys H, Smyth E, Phillips J, Cunney R, Mc Namara E, et al: A twelve-year review of central nervous system bacterial abscesses; presentation and aetiology. Clin Microbiol Infect 9:803-809, 2003

80. Rosenblum ML, Mampalam TJ, Pons VG: Controversies in the management of brain abscesses. Clin Neurosurg 33:603-632, 1986

81. Rosenfeld EA, Rowley AH: Infectious intracranial complications of sinusitis, other than meningitis, in children: 12-year review. Clin Infect Dis 18:750-754, 1994

82. Salzman C, Tuazon CU: Value of the ring-enhancing sign in differentiating intracerebral hematomas and brain abscesses. Arch Intern Med 147:951-952, 1987 


\section{E. Erdoğan and T. Cansever}

83. Sandrock D, Verheggen R, Helwig AT, Munz DL, Markakis E, Emrich D: Immunoscintigraphy for the detection of brain abscesses. Nucl Med Commun 17:311-316, 1996

84. Schliamser SE, Bäckman K, Norrby SR: Intracranial abscesses in adults: an analysis of 54 consecutive cases. Scand J Infect Dis 20:1-9, 1988

85. Schroeder KA, McKeever PE, Schaberg DR, Hoff JT: Effect of dexamethasone on experimental brain abscess. J Neurosurg 66:264-269, 1987

86. Schroeder PC, Post MJ, Oschatz E, Stadler A, Bruce-Gregorios J, Thurnher MM: Analysis of the utility of diffusion-weighted MRI and apparent diffusion coefficient values in distinguishing central nervous system toxoplasmosis from lymphoma. Neuroradiology 48:715-720, 2006

87. Sennaroglu L, Sozeri B: Otogenic brain abscess: review of 41 cases. Otolaryngol Head Neck Surg 123:751-755, 2000

88. Seydoux C, Francioli P: Bacterial brain abscesses: factors influencing mortality and sequelae. Clin Infect Dis 15:394-401, 1992

89. Sharma BS, Banerjee AK, Sobti MK, Kak VK: Actinomycotic brain abscess. Clin Neurol Neurosurg 92:373-376, 1990

90. Sharma BS, Gupta SK, Khosla VK: Current concepts in the management of pyogenic brain abscess. Neurol India 48:105-111, 2000

91. Smith RR: Neuroradiology of intracranial infection. Pediatr Neurosurg 18:92-104, 1992

92. Stapleton SR, Bell BA, Uttley D: Stereotactic aspiration of brain abscesses: is this the treatment of choice? Acta Neurochir (Wien) 121:15-19, 1993

93. Stephanov S, Joubert MJ: Large brain abscesses treated by aspiration alone. Surg Neurol 17:338-340, 1982

94. Takeshita M, Kagawa M, Izawa M, Takakura K: Current treatment strategies and factors influencing outcome in patients with bacterial brain abscess. Acta Neurochir (Wien) 140:12631270, 1998

95. Takeshita M, Kagawa M, Yato S, Izawa M, Onda H, Takakura K, et al: Current treatment of brain abscess in patients with congenital cyanotic heart disease. Neurosurgery 41:1270-1279, 1997

96. Tekkök IH, Erbengi A: Management of brain abscess in children: review of 130 cases over a period of 21 years. Childs Nerv Syst 8:411-416, 1992
97. Tsai JC, Teng LJ, Hsueh PR: Direct detection of bacterial pathogens in brain abscesses by polymerase chain reaction amplification and sequencing of partial 16S ribosomal deoxyribonucleic acid fragments. Neurosurgery 55:1154-1162, 2004

98. Tseng JH, Tseng MY: Brain abscess in 142 patients: factors influencing outcome and mortality. Surg Neurol 65:557-562, 2006

99. Van Alphen HA, Dreissen JJ: Brain abscess and subdural empyema. Factors influencing mortality and results of various surgical techniques. J Neurol Neurosurg Psychiatry 39:481490, 1976

100. Vogelsang JP, Wehe A, Markakis E: Postoperative intracranial abscess - clinical aspects in the differential diagnosis to early recurrence of malignant glioma. Clin Neurol Neurosurg 100: $11-14,1998$

101. Whelan MA, Hilal SK: Computed tomography as a guide in the diagnosis and follow-up of brain abscesses. Radiology 135: 663-671, 1980

102. Wise BL, Gleason CA: CT-directed stereotactic surgery in the management of brain abscess. Ann Neurol 6:457, 1979

103. Xiao F, Tseng MY, Teng LJ, Tseng HM, Tsai JC: Brain abscess: clinical experience and analysis of prognostic factors. Surg Neurol 63:442-450, 2005

104. Yang SY: Brain abscess: a review of 400 cases. J Neurosurg 55:794-799, 1981

105. Yang SY, Zhao CS: Review of 140 patients with brain abscess. Surg Neurol 39:290-296, 1993

106. Young JD, McGwire BS: Infliximab and reactivation of cerebral toxoplasmosis. N Engl J Med 353:1530-1531, 2005

107. Zeidman SM, Geisler FH, Olivi A: Intraventricular rupture of a purulent brain abscess: case report. Neurosurgery 36:189-193, 1995

Manuscript submitted February 15, 2008.

Accepted February 22, 2008.

Address correspondence to: Tufan Cansever, M.D., Gulhane Askeri Tip Akademisi, Nörosirürji AD Etlik, Ankara, Turkey 06016. email: drtufan@gmail.com. 